\title{
EL CONTROL CAMPESINO Y JORNALERO DE LOS AYUNTAMIENTOS DE LA ALTA ANDALUCÍA DURANTE LA CRISIS DE LOS AÑOS TREINTA (1931 - 1939)
}

\author{
por \\ FRANCISCO COBO ROMERO \\ Universidad de Granada.
}

RESUMEN: El presente estudio pretende demostrar el enorme valor que adquirió el control del poder local en Andalucia -y para ello utilizamos el soporte empirico de la Alta Andalucia- durante el periodo republicano inmediatamente precedente al estallido de la Guerra Civil de 1936-39. Los ayuntamientos se convirtieron, entre 1931 y 1936 , en piezas clave empleadas de manera diferenciada por los distintos grupos sociales rurales para satisfacer sus especificos intereses materiales y culturales en una coyuntura de crisis politica y económica. El campesinado utilizó los ayuntamientos, durante el primer bienio republicano, para reforzar su control sobre el mercado de trabajo e imponer a los patronos el cumplimiento de las bases del trabajo. La reacción patronal del segundo bienio llevó de nuevo a la burguesia agraria al control municipal, y desde aquí intentó reimplantar el viejo orden caciquil. La llegada del Frente Popular radicalizó las posturas sociales y condujo al conflicto civil de 1936, en el que los ayuniamientos volvieron a desempeñar un papel decisivo.

Palabras clave: Poder local, Alta Andalucia, II República, Guerra Civil, Conflicto rural, control del poder local.

ABSTRACT: Using the case of Eastern Andalusia for empirical support, this paper argues that the control of local power in Andalusia during the Republican period immediately preceding the Civil War was of paramount importance. Between 1931 and 1936, municipal governments played a crucial role, as they were used by different rural groups to satisfy their specific material and cultural needs in the midst of a political and economic crisis. During the first Republican biennium, rural workers used municipal governments to reinforce their control of the job market, foring landowners strictly to apply labour legislation. The landowners reaction during the second biennium put the rural bourgeoisie back into municipal governments, who used them to reestablish the old oligarchic system. With the adnent of the Popular Front, social issues became more radical, ultimately leading up to the Civil War in 1936, where once again municipal governments played a decisive role.

KEY WORDS: Local power, Eastern Andalusia, Second Republic, Civil war, Rural conflict, control of municipal governments.

Hispanta, LIX/1, nưm. 201 (1999) 75-96 
A través de las siguientes páginas queremos efectuar un recorrido por las variaciones que experimentaron las funciones del poder municipal, y los diferentes usos que del mismo hicieron los principales grupos sociales de las comunidades rurales de la Alta Andalucía. El periodo cronológico objeto de nuestro análisis será el comprendido entre 193 —año de la proclamación del régimen democrático de la II República - y 1939 —en que finalizó el conflicto civil y dio comienzo, en tierras de la Alta Andalucía, el régimen dictatorial franquista.

Queremos poner de manifiesto cómo, una vez iniciada la etapa de creciente fortalecimiento de las organizaciones políticas y sindicales de signo izquierdista que acogieron a la mayor parte del campesinado organizado altoandaluz desde los comienzos del siglo $\mathrm{XX}$, las relaciones entre campesinos y patronos agtícolas fueton mostrándose cada vez más virulentas e irreconciliables. Esta progresiva radicalización — sustentada por una segmentación horizontal cada vez más evidente--, así como la polarización social propiciada por la expansión del mercado y el capitalismo agrario, se convirtieron en fenómenos articulados preferentemente, por lo que respecta a la Alta Andalucía, en torno al poder local como máxima expresión política e ideológica reguladora de las comunidades rurales.

Una vez fracasado el sistema caciquil tradicional, la implantación del régimen republicano coincidió con el inicio de una intensa crisis agraria, la acumulación de ricas experiencias por parte del campesinado en cuanto al uso privilegiado que hicieron del poder municipal las oligarquías rurales, y el fortalecimiento de la capacidad reivindicativa de los jornaleros.

La conjunción de tales factores, se vio sedimentada por el impulso que el socialismo reformista otorgó a la participación política de los campesinos en las instancias locales. La llegada de los representantes de los jornaleros y campesinos pobres a la mayor parte de los ayuntamientos de los pueblos y ciudades altoandaluces, coincidió con un momen: o histórico en que las divisiones ideológicas y materiales entre los grupos rutales se habían ido incrementando sucesivamente. El uso instrumental que los campesinos hicieton de los ayuntamientos durante el primer bienio republicano fue conducido hacia la satisfacción de sus intereses históricos, lo cual perjudicó enormemente a la burguesía agraria, e incluso a algunas otras fracciones de los pequeños y medianos arrendatarios y propietarios agrícolas. Las luchas agrarias en muchos pueblos de la Andalucía Oriental se vertebraron en torno a los ayuntamientos, lo cual propició una clarificación de las posturas opuestas que sostenían grupos sociales abiertamente enfrentados. El infructuoso intento de los ricos propietarios agrícolas de regresar a las fórmulas caciquiles y oligárquicas municipales ensayadas durante mucho tiempo atrás, y la reedición de estrategias patronales orientadas hacia el incumplimiento de la legislación reformista y la sobreexplotación de la mano de obra rural, se tradujeron en la radicalización de buena parte de los jornaleros hacia los comienzos del año 1936. El fracaso de los intentos patronales por recuperar el poder municipal mediante las vías legalmente establecidas ensayados durante el «bienio negro», inclinó a muchos miembros de la

Hipania, LIX/1, num. 201 (1999) 75-96 
burguesía agtaria hacia la defensa de posturas rupturistas, autoritarias, violentas y declaradamente militaristas, que desembocaron en el apoyo rotundo a la intentona golpista del verano de 1936. La guerra civil acentuó el carácter de clase, e incluso revolucionatio, que adquirió la acción de los jornaleros al frente de los comités populares y los ayuntamientos, fenómeno este último que se tradujo, finalmente, en la especial virulencia con que reaccionaron los patronos agrícolas - $\tan$ seriamente perjudicados durante el transcurso del conflicto- una vez instaurado el régimen franquista. Asimismo, durante el transcurso del conflicto, y muy especialmente a lo largo del verano y el otoño de 1936, las acciones revolucionarias de los jornaleros de numerosos pueblos de la retaguardia, perjudicaron los intereses de algunos pequeños propietarios y arrendatarios. Se procedió a la expropiación de algunas fincas rústicas de modestas dimensiones, quizá como medida dirigida contra todos aquellos que, de alguna u otta forma, mostraron simpatia por las posturas patronales y antirrepublicanas durante los años inmediatamente precedentes. Este último fenómeno acentuó las fracturas ya existentes en el seno mismo del campesinado altoandaluz, y predispuso a buena parte de los campesinos pobres perjudicados por el radicalismo jornalero hacia un apoyo tácito a las propuestas de fascismo agratio avanzadas por las autoridades del bando rebelde. En suma, pues, pensamos que durante la conflictiva década de los treinta, el particular uso que hicieron del poder municipal los distintos grupos de las comunidades rurales, contribuyó al ahondamiento del fenómeno de polarización social, convirtiéndose los ayuntamientos en instancias políticas y administrativas vertebradoras de las múltiples luchas agrarias desencadenadas en este período.

\section{LA CRISIS DEL, CACIQUISMO Y DEL SISTEMA OLIGÁRQUICO LIBERAL EN LA ALTA ANDALUCÍA}

Las características mostradas por las estrategias productivas que adoptaron las oligatquías rurales andaluzas de cara a la resolución de los efectos de la crisis agratia finisecular estuvieron revestidas de una naturaleza esencialmente conservadora. Se optó por la implantación de soluciones puramente extensivistas, que ampliaron la frontera agtaria al intensificarse el tecurso a los cultivos tradicionales —olivo y cereales, preferentemente (Gehr, 1988; Jiménez Blanco, J., 1986 y Garrabou, R., 1986) - Resultaron de esta manera preteridas otras soluciones más audaces y de claro contenido modernizador, tales como la sustitución de los cultivos tradicionales por cultivos industriales y alternativos, la incipiente mecanización de los procesos de trabajo agrícolas o la sustitución progresiva de insumos y fertilizantes orgánicos o de origen natural por otros abastecidos por la naciente industria quimica. Las medidas proteccionistas arbitradas desde las instancias politicas estatales y la situación hegemónica y privilegiada detentada por las oligarquías rurales privilegiadas permitieron, de una parte, el mantenimiento artificial de precios remuneradores para los cultivos tradicionales, y de otra la ampliación de superficies cultivadas a costa de la privatización constante de espacios montuosos, forestales y de integración agro-

Hippania, LIX/1, núm. 201 (1999) 75-96 
silvo-pastoril de anterior aprovechamiento comunal o vecinal (Cobo, F; Cruz, S. y González De Molina, M., 1992).

De esta forma, el capitalismo agrario arcaico prevaleciente en la Alta Andalucía apenas experimentó modificaciones sustanciales. Continuó siendo un sistetma de explotación y uso de la tierra y los recursos naturales asentado básicamente sobre una economía orgánica que requería insumos proveídos por la tierra, el agua, los fertilizantes naturales, las enetgías renovables y la mano de obra campesina o jornalera (González De Molina, 1993).

Asimismo, la situación del campesinado altoandaluz experimentó algunas modificaciones en el tránsito de los siglos XIX al XX. De una parte, la privatización de uso y jurídica de amplios espacios agrarios de anterior aprovechamiento común, mayoritariamente en beneficio de los intereses de las minorías rurales privilegiadas, constriñó seriamente las posibilidades de obtención de bienes necesarios para la reproducción de los grupos familiares campesinos de la forma en que habia sido frecuente desde mucho tiempo atrás (Cobo, F; Cruz, S. y González De Molina, M., 1992). Esto último condicionó una mayor dependencia del campesinado del mercado capitalista en expansión, de tal forma que muchos de los bienes y servicios que antes se apropiaba mediante su directa extracción de los montes y espacios comunales, ahora debía lograrlos en el mercado. De otra parte, la expansión de las superficies cultivadas y la privatización creciente de la tierra disponible — resultante de la superación de la crisis agraria gracias al empleo de fórmulas extensivistas y conservadoras- dificultaron sobremanera las estrategias campesinas tradicionales para asegurarse el uso de la tierra —arrendamiento, aparcería, pequeña propiedad, etc.- $\mathrm{La}$ conjunción de las circunstancias descritas se tradujo en un incremento de las relaciones salariales y de contratación de la mano de obra entre el conjunto de los grupos sociales rurales altoandaluces, pero muy especialmente entre el campesinado, de un lado, y los medianos y grandes propietarios y arrendatarios agtícolas, de otro. El fenómeno de la salarización y de la mercantilización progresiva de las economías campesinas condujo hacia la , nodificación gradual de los comportamientos conflictivos, al ahondamiento ce las segmentaciones horizontales de la estructura social rural y al reforzamiento de las reivindicaciones salariales sostenidas por conjuntos cada vez más amplios del campesinado (Cruz Artacho, S., 1994).

Así pues, los viejos alineamientos verticales que sostenían las relaciones de patronazgo y clientelares entre oligarquías rurales y grupos de campesinos pobres y jornaleros, se fueron debilitando a medida que transcurrian las primeras décadas del siglo XX y surgían, con fuerza hasta enitonces desconocida, los sindicatos de obreros agrícolas de signo izquierdista e incluso revolucionario (Calero, A.M., 1979; Diaz Del Moral, J., 1979 y Cruz Artacho, S., 1994).

Ante esta nueva realidad, la respuesta de las clases patronales consistió en la protección de sus intereses mediante el estricto control de los poderes municipales, para desde ellos asegurar la reproducción de las nuevas condiciones sobre las que se asentaba la explotación de la mano de obra, teniendo en cuenta que este último factor continuaba siendo decisivo en la organización de la pro-

Haipania, LIX/1, núm 201 (1999) 75-96 
ducción agrícola altoandaluza. Desde los ayuntamientos, las oligarquías rurales continuaron asegurándose un favorable reparto de las cargas impositivas, una asignación satisfactoria de los aprovechamientos forestales y de montes, la obtención de fuentes energéticas indispensables para la puesta en marcha de los procesos de trabajo, y, por último, un fuerte disciplinamiento del mercado labotal, en una coyuntura decisiva en que el campesinado edificaba instrumentos de resistencia cada vez más poderosos (Cobo, F. y otros, 1992).

Las etapas altamente conflictivas de los primeros años del siglo XX y el llamado "trienio bolchevique» obligaron a los patronos agrícolas a reforzar sus estrategias caciquiles para seguir controlando los ayuntamientos, contando, eso sí, con el concurso inestimable de las fuerzas del orden dirigidas desde el estado central. El empleo generalizado de la violencia y la utilización marcadamente de grupo o de clase de los ayuntamientos, convirtieton a las prácticas caciquiles en expresiones consustanciales a la defensa de los intereses de las minorías dominantes en cada pueblo o ciudad de la Alta Andalucía.

Sin embargo, y pese a la transitoria adopción de una forma de gobierno dictatorial que a partir de 1923 reforzó las posiciones de dominio de la burguesía agratia en el ámbito de sus dificultosas telaciones con el campesinado en Andalucía, la crisis del sistema caciquil resultó inevitable cuando, desde 1931, una nueva correlación de fuerzas sociales, y la instalación en el poder del estado de un nuevo bloque de clases posibilitaron la proclamación de un régimen político democrático y parlamentario.

\section{EL CONTROL CAMPESINO Y POPULAR DE LOS AYUNTAMIENTOS DURANTE LA CRISIS DE LOS AÑoS TREINTA}

Una vez concluida la experiencia dictatorial, las funciones básicas del poder local permanecieron casi inalteradas. En torno al poder local se habían articulado, desde mucho tiempo atrás, las pugnas entre los distintos grupos sociales rurales en torno al aprovechamiento de la tierra y la definición de modelos específicos de gestión económica y aprovechamiento de los recursos agrícolas y naturales.

La experiencia jornalera y campesina en torno a los ayuntamientos en el pasado - especialmente durante la etapa de crisis del caciquismo- había resultado, pues, decisiva. La II República significó la fusión de una situación catacterizada por el reconocimiento e impulso de los órganos sindicales y políticos de resistencia campesina frente al capitalismo agrario, por una parte, y la existencia de los ayuntamientos como instancias reguladoras de la vida local y con amplias atribuciones en todo lo concerniente a la organización de los factores productivos, regulación del mercado de trabajo y establecimiento de pautas ordenadoras de las relaciones productivas entre jornaleros y patronos agricolas, por otra.

A esto último debe añaditse la existencia de una aguda crisis agratia, en medio de la cual los patronos precisaron una absoluta constricción del poder campesino para hacer frente a sus efectos (Cobo Romero, F., 1992; Palafox, J., 1991 y

Hijpantu, L.IX/1, núm. 201 (1999) 75-96 
Hernández Andreu, J., 1980). Para la realización de tal logro, el control de los ayuntamientos volvió a convertirse en crucial, pero al mismo tiempo, la fortaleza política y sindical del campesinado - particularmente de los jornaleros-y su determinación por implantar pautas de comportamiento económico próximas a los ideales insertos en su «economía morab) (Thompson, E.P., 1971 y 1986), motivaron un fuerte posicionamiento político de los jornaleros y campesinos pobres en torno a los poderes locales. Los colectivos turales de cada comunidad de la Alta Andalucía se polarizaron enormemente durante los años del primer bienio republicano, pues los campesinos se sintieron fuertemente sensibilizados por las propuestas reformistas - muy próximas a las reivindicaciones tradicionales del campesinado- de las izquierdas, mientras que los patronos, deseosos de restaurar el viejo orden de cosas - caciquil y oligárquico - para hacer frente satisfactoriamente a la crisis, se sintieron agredidos por el régimen republicano y por las nuevas autoridades municipales de izquierdas, a las que consideraban incapacitadas para el ejercicio del poder. La lucha en torno a los ayuntamientos mostró rasgos de marcada diferenciación ideológica, política y social; surgió del profundo distanciamiento entre jornaleros y campesinos pobres de una parte, y patronos agrícolas acomodados, de otra, que se inició con la tesolución de la crisis agtaria finisecular, pero que se agudizó profundamente en una situación de libertades políticas formales y fortalecimiento extremado de las organizaciones campesinas. Los patronos intentaron recuperar el poder local para reconducir la situación económica y social de los pueblos y comarcas altoandaluzas en el sentido del reforzamiento de las prácticas del capitalismo agtario y del mercado. Ante el fracaso registrado por esta tentativa a partir de febrero de 1936, la gran patronal agraria altoandaluza, habiendo logrado -mediante fenómenos de cooptación ideológica - el apoyo de algunas fracciones del campesinado propensas hacia un cambio político que reintrodujese disciplina y orden en el mercado laboral y apaciguase a buena parte de los jornaleros, comenzó a optar decididamente, hacia la primavera de 1936, por soluciones autoritarias cuando no claramente fascistas. Los orígenes de la guerra civil en Andalucía, pueden hallarse en la forma particular en que se resolvió un complejo enfrentamiento de posiciones sociales que revistió múltiples caracteres, pero que sin duda alguna se articuló, en muy buena medida, a través de los ayuntamientos.

\subsection{Alcaldes de izquierda "versus" orden patronal}

La proclamación del régimen republicano en abril de 1931, suscitó, sin lugar a dudas, expectativas entre amplios colectivos rutales de la Alta Andalucía, hasta el extremo de que importantes sectores del campesinado llegaron a identificar plenamente la esencia democrático-parlamentaria de que se hallaba investida la II República con un nuevo «status» jurídico-político que, por primera vez, venía a confirmar la posibilidad de una futura edificación de la anhelada «economía moral» campesina.

Hispania, LIX/t, núm 201 (1999) 75-96 
El proceso político aperturista inaugurado con la República pronto se vio seriamente obstaculizado por dificultades de naturaleza económica y política, que suscitaron no pocos enfrentamientos. La crisis económica, aún cuando sus manifestaciones más perniciosas se mostrasen considerablemente atenuadas en nuestro país, debido al particular «atraso» de nuestras estructuras productivas, repercutió muy desfavorablemente sobre el sector de exportación de productos agrícolas (Hernández Andreu, J., 1980). El acusado descenso de los precios del aceite y del trigo (sin mencionar las reducciones en el valor de mercado experimentadas por otros cultivos ampliamente representativos de la agricultura mediterránea) colocó a numetosas explotaciones agrícolas, generalmente regentadas por medianos y grandes propietarios y arrendatarios, en situaciones francamente deficitarias (Garrido González, L., 1990 y Cobo Romero, F., 1992). La pérdida de rentabilidad de la gran propiedad agtícola, provocó entre la clase patronal actitudes enconadas en favor de la sujeción absoluta de la mano de obra campesina a fin de lograr su inmediata sobreexplotación. Teniendo en cuenta que la vía de la mecanización de las explotaciones agricolas se hallaba obstaculizada desdé 1931 ó 1932 por una aguda resistencia campesina, los titulares de las medianas y grandes explotaciones agrícolas optaron por la adopción de mecanismos económicos que garantizasen el incremento de la plusvalía absoluta, para hacer frente de manera efectiva a la disminución de beneficios causada por las constricciones del mercado externo de productos y la imparable disminución del valor de lo cosechado (Cobo Romero, F., 1992).

La legislación social reformista del primet bienio (1931-1933) reforzó el papel de los Ayuntamientos en la regulación del mercado de trabajo, hasta el extremo que la utilización «de clase» del poder local que hizo el campesinado, a través de sus representantes, desarticuló abiertamente las relaciones de dominación existentes hasta ese momento en el mundo rural altoandaluz. Mediante el decreto de 7 de mayo de 1931, denominado de Laboreo Forzoso (elevado a Ley el 23 de Septiembre de 1931 ), los propietarios agtícolas quedaban obligados a cultivar sus tierras según los «usos y costumbres» de buen labrador, incluyéndose en su articulado la amenaza implícita, a cuantos incumpliesen sus disposiciones, con el arrendamiento de sus propiedades a los colectivos de obreros agtícolas legalmente constituidos. La aplicación de tal decreto permitía la creación de las Comisiones Técricas de Laboreo Forzoso, Ias Juntas Locales Agrarias y las Comisiones de Policía Rural. Todas ellas se encargaban de dictaminar el cuadro de labores imprescindibles en cada zona, así como de la supervisión del grado de cumplimiento de lo prescrito por las disposiciones sobre Laboreo Forzoso. Tanto las Juntas Locales como las Comisiones de Policía Rural estaban presididas por el alcalde de la localidad donde estuviesen radicadas. A ellas correspondía la determinación de la urgencia confetida a ciertas labores, atribuyéndose a tales cuerpos funciones de asignación de campesinos en situación de paro forzoso, para su colocación temporal en aquellas fincas donde se estimase oportuna la realización de tales faenas. Y todo ello aun a pesar de que el titular (propietario, arrendatario, etc.) de las mismas se abstuviese de cumplir 
lo preceptuado por los órganos centrales y provinciales encargados de la efectiva ejecución de la Ley. De esta forma, los propietarios y arrendatarios rurales venían obligados a dar empleo, a lo largo del año, a un número concreto de campesinos en las fincas por ellos regentadas, con lo cual se diluían enormemente los lazos de dependencia económica que de manera tradicional habían ligado al campesinado frente a los propietarios acomodados de extensas comarcas de la Âlta Andalucía. Ello provocó, como era de esperar, una abultadísima oleada de protestas patronales, que denotaban la virulenta oposición, mostrada por los miembros de las clases sociales rutales privilegiadas, hacia las disposiciones legislativas de los gobiernos reformistas del primer bienio.

Para hacer frente al acuciante problema del paro forzoso en la agricultura, se sustituyeton los decadentes alojamientos por un sistema tributario, cuya recaudación era destinada a la edificación de un fondo orientado hacia la subvención de aquellas obras públicas que absorbiesen mano de obra en situación de desempleo (Malefakis, E., 1982 y Collier, G.A., 1997). El recargo impositivo, gestionado por los Ayuntamientos, se establecía en una décima parte de las contribuciones territorial e industrial, siendo su ámbito de aplicación, en un principio, las provincias andaluzas y extremeñas. Simultáneamente, se concedieron ayudas económicas especiales a los pueblos para que fuesen distribuidas entre los desocupados. Al mismo tiempo, la regulación de la contratación de trabajadotes, cualesquiera que fuese su naturaleza profesional, apareció materializada tras la promulgación de la Ley de Colocación Obrera de 27 de Noviembre de 1931. En la misma se establecía la creación de una red de Oficinas de Colocación municipales, provinciales, mancomunadas o regionales, sometidas a la inspección de Comisiones integradas por representaciones patronales y obreras, a las que se añadiría una «(...) representación de personalidades competentes, pertenezcan o no a la Administración Pública, nombradas a propuesta de las respectivas entidades por el Ministerio de Trabajo y Previsións. En todos los casos, el presidente de las Comisiones Inspectoras de las oficinas de colocación, debía ser un obrero, designado mediante acuerdo de los miembros componentes de las mismas. Si no se obtuviese tal acuerdo, sería nombrado por el Ministerio de Trabajo, previa presentación de ternas por cada una de las representaciones profesionales y por el Delegado de Trabajo provincial. Se dictaba, asimismo, la creación de un registro municipal, radicado en las Alcaldías de los Ayuntamientos, con las inscripciones diarias de las ofertas y demandas de trabajo. En las cabeceras de partido judicial, las capitales de provincia y en aquellas localidades más importantes de cada provincia donde se considerase oportuno, se crearían oficinas de colocación, con las necesarias secciones pata los diversos ramos de la agricultura, la industria, el comercio o las actividades profesionales domésticas. De esta forma, la inscripción de los trabajadores agrícolas en paro, así como su contratación pot los propietarios rurales, comenzaban a constituirse en relaciones económicas y jurídicas entre las clases sociales rurales controladas, en muy buena medida, por los miembros de los grupos sociales rutales populares a través de sus representantes políticos locales. La supervisión por parte de los alcaldes izquierdistas, y de las sociedades

Hiponia, LIX/1, núm. 201 (1999) 75.96 
obreras agtícolas, de los registros de inscripción de campesinos parados (comúnmente denominados Bolsas de Trabajo), y la obligatoriedad que recaía sobre los patronos para que contrataran a los trabajadores que necesitasen, solicitándolos de las oficinas municipales de colocación obrera, y respetando rigurosamente el orden de inscripción de parados en la Bolsa de Trabajo, se convertirían, a medida que progresaba el fortalecimiento de las instituciones republicanas, en realidades contestadas con frecuente acritud por las clases sociales rurales dominantes. Sobre todo, porque estas últimas perseguían, ante todo, mantener viejas situaciones de privilegio en la contratación, mediante la marginación sistemática de los campesinos más declaradamente vinculados a las organizaciones políticas y sindicales de izquierda (Garrido González, L., 1987 y Cobo Romero, F, 1992).

Los alcaldes, en su mayoría de izquierda durante el transcurso del primer bienio republicano ${ }^{1} \mathrm{y}$ vinculados estrechamente a las exigencias y reivindicaciones de toda índole procedentes del campesinado, interferían continuamente en las relaciones económicas entre campesinos y propietarios agrícolas acomodados. Las primeras autoridades municipales dictaban a menudo bandos prohibiendo el uso de maquinaria agtícola, fijando especiales condiciones de trabajo en el campo o resolviendo contenciosos laborales en favor del campesinado. En su calidad de representantes directos de los máximos responsables provinciales en la resolución de desavenencias surgidas en las relaciones labotales en el campo, en aquellas localidades donde no existían Jurados Mixtos del Trabajo Rural, los alcaldes entendían de múltiples asuntos referidos al cumplimiento de lo acordado en las Bases reguladoras de las labores agrícolas. En este sentido, resolvian frecuentemente en favor de los jomaletos y campesinos pobres siempre que los patronos se negaban a cumplir alguno de los acuerdos estipulados en los documentos oficiales aprobados por los jurados Mixtos. En muchas ocasiones durante el primer bienio, los alcaldes socialistas de las provincias de Jaén y Granada, presidieron comisiones arbitrales que, bajo la supervisión de los presidentes de los Jurados Mixtos, elaboraron acuerdos entre patronos y trabajadores rurales de cara a la regulación de las condiciones de trabajo en el campo. En muchos casos analizados, la presión de las organizaciones campesinas, y la activa labor mediadora del alcalde en favor de los intereses de estas últimas, arrojaron acuerdos locales sumamente beneficiosos para el campesinado en su conjunto.

1 Tras las elecciones municipales de 12 de abril de 1931, las candidaturas republicano-socialistas obtuvieron el $64,3 \%$ de los concejales electos en la provincia de Jaén. Tras la repetición, en abril de 1933, de las elecciones locales en aquellos municipios donde en abril de 1931 se había aplicado el artículo 29 de la entonces vigente Ley Electoral, los candidatos socialistas —que ahora acudian en solitario- vencieron ampliamente. Cf. COBO ROMERO, F., (1992; 234 y 240 ). Por lo que respecta a la provincia de Granada, en mayo de 1932 los ayuntamientos controlados por las izquierdas alcanzaban en algunas comarcas porcentajes situados entre el 60 y el 80 por cien del total de municipios ubicados en ellas. Cf. López Mar'rínez, M. (1995; 235).

Hípunia, LIX/1, núrn. 201 (1999) 75-96 
Durante el primer bienio republicano, las Casas del Pueblo y los centros obreros locales, se habían convertido en lugares de reunión periódica de los campesinos organizados más conscientes de cada localidad, donde se efectuaba un cotidiano intercambio de expetiencias, $y$ donde se solidificaba diariamente una vivencia colectiva asentada sobre el conocimiento mutuo de los conflictos y actos de resistencia protagonizados por los jornaleros contra los patronos agrícolas más reacios al cumplimiento de lo dispuesto en la legislación reformista (Cobo Romero, F., 1992). Las directivas de las Casas del Pueblo, que hacia 1933 existían en la práctica totalidad de los pueblos de la Andalucía Oriental -y muy preferentemente en las comarcas de predominio de la gran propiedad de las provincias de Granada y Jaén ${ }^{2}$ - integradas mayotitariamente por aquellos campesinos más activos, permanecian en un constante entendimiento con los alcaldes y concejales socialistas —o simplemente de izquierdas- de la tespectiva localidad donde aquéllas estuviesen radicadas. Desde estas instancias se sugerían las decisiones adoptadas por las primeras autoridades locales de cara a la resolución de los múltiples enfrentamientos sostenidos por las clases sociales rurales (López Martínez, M., 1995 y Cobo Romero, F, 1992).

Puede afirmarse que los dos bastiones más firmes sobre los que se instalaba la influencia campesina local durante la mayor parte de la etapa republicana anterior a la guerra civil fueron los ayuntamientos y las sociedades obreras agricolas de cada localidad. En torno al ayuntamiento y las casas del pueblo se aglutinaban la mayor parte de los jornaleros y campesinos de izquierda más conscientes, y desde allí articulaban sus prácticas de lucha contra el sesgo predominantemente patronal, mercantilista y capitalista que habían adquirido las relaciones entre los grupos sociales rutales durante la etapa de crisis agraria de fines de la década de los veinte y principios de la de los treinta.

Así pues, desde los Ayuntamientos, el campesinado (y muy especialmente los jornaleros organizados) ejerció una constante labor de vigilancia en torno al estricto cumplimiento pattonal de la legislación laboral reformista del primer bienio. Las Corporaciones Municipales controladas por el PSOE y la FNTT se convirtieron en firmes baluartes de la defensa de los intereses materiales y culturales del campesinado pobre y los jornaleros. De esta forma, se vio seriamente amenazada la continuidad del viejo edificio rutal, diseñado en consonancia con las necesidades de teproducción de la gran propiedad rústica. Por ello el mayor empeño de la patronal y sus asociaciones consistió, a medida que avanzaba la experiencia republicana, en el desalojo de los Ayuntamientos de todos los representantes de izquierda del campesinado. Una vez que se hubo instalado en el poder central del Estado una nueva coalición de fuerzas políticas conservadoras

2 Según los datos aportados por Matio LópEZ (1995; 200), en el año 1933 existian en la provincia de Granada 202 sociedades obreras de campesinos adscritas a la FNT'T ugetista, siendo el total de localidades existentes en la provincia en aquel entonces de 201 . Todo parece indicar que la red de organizaciones campesinas ugetistas se extendió a lo largo de toda la geografia provincial.

1litprania, 1,IX/1, núm. 201 (1999) 75-96 
y agraristas desde noviembre de 1933, la patronal inició una amplia ofensiva contra los Ayuntamientos de izquierda. A lo latgo del año 1934, y sobre todo tras el fracaso de la huelga campesina de junio y las tímidas manifestaciones de descontento de octubre de ese mismo año, fueron destituidas la práctica totalidad de las Corporaciones Municipales andaluzas regentadas por alcaldes de izquierda, y sustituidas por Comisiones Gestoras presididas por notables locales vinculados a los intereses agrarios de la gtan patronal, o por miembros destacados de los partidos tepublicanos conservadores (Partido Republicano Radical, CEDA) o netamente agratistas (López Martínez, M., 1995 y Cobo Romero, F., 1992).

Durante el período de reacción patronal y agratista, desplegado a lo largo de los años 1934 y 1935, los alcaldes y concejales derechistas reimplantaton prácticas de control social que, no solamente ahondaron las graves fisuras que ya mostraba la estructura social de numerosas comunidades rurales, sino que asimismo prefiguraron buena parte de los hábitos de poder oligárquico que se hatían efectivos mediante la implantación del régimen franquista en Andalucía.

Las clases patronales definieron una estrategia de recuperación del perdido control sobre los Ayuntamientos, entendidos como piezas administrativas con funciones primordiales de tegulación de las relaciones laborales con el campesinado. Desde las Corporaciones locales, los patronos pretendían también reconstruir el entramado de mecanismos de control social, ideológico y cultural que asegurasen la reedificación de las condiciones materiales y «extramateriales" garantizadoras de la reproducción de las funciones económicas de la gran propiedad rústica.

$\mathrm{La}$ amalgama de todo este variado conjunto de factores, propició el advenimiento de una etapa histórica - la de los primeros años treinta- caracterizada por la progresiva radicalización de las posturas del campesinado, en defensa de sus aspiraciones en torno al libre uso y aprovechamiento de la tierta, y el consiguiente incremento de las luchas y confrontaciones entre las clases sociales rurales.

La victoria del Frente Popular, la reconstitución de los órganos de resistencia del campesinado, y el regreso a los Ayuntamientos de los representantes campesinos de izquierda, inauguraron una nueva etapa donde el clamor unánime de las clases rurales subordinadas se traducía en la exigencia de la colectivización de la tierra, y la radical transformación de las relaciones de producción aún subsistentes.

\subsection{La coyuntura bélica. El control jornalero del poder local}

La guerra civil de 1936 introdujo cambios sustanciales en la economía, la vida política y los comportamientos de los habitantes de los pueblos y ciudades de las comarcas rurales altoandaluzas que permanecieron leales a las autoridades republicanas. Las transformaciones fueron especialmente significativas en el ámbito de las pautas culturales, ideológicas y materiales que regían las rela- 
ciones entabladas entre los diferentes grupos sociales. Durante los primeros meses del conflicto, la vida cotidiana de innumerables pueblos experimentó una profunda alteración. Los grupos sociales privilegiados, las oligarquías rurales que habían ocupado posiciones dominantes en los ámbitos del poder municipal, así como los sectores sociales intermedios que habían contribuido tradicionalmente a sostener el edificio de telaciones de dominación y explotación de los ricos propietarios agrícolas sobre el campesinado —especialmente sobre los campesinos más pobres y los jornaleros-, comenzaron a padecer, después de las convulsiones políticas y sociales del verano de 1936, una situación de persecución y marginación, e incluso algunos destacados derechistas fueron violentamente exterminados.

En la práctica totalidad de los pueblos de Andalucía Oriental se registraton actos revolucionarios, mayoritariamente protagonizados por grupos de jornaleros, o de integrantes de los sectores más humildes de la sociedad rural, que perseguían de esta forma la instauración de un nuevo orden económico y político, que impidiese el regreso a situaciones históricas precedentes. Los saqueos de las viviendas de los ricos propietarios agrícolas, así como de los jueces municipales, abogados $\mathbf{u}$ otros individuos identificados con el viejo orden caciquil sobre el que se sostuvo el sistema predominante de la gran propiedad rural, fueron frecuentes durante los meses de julio a septiembre de 1936. Asimismo, el patrimonio histórico-artístico perteneciente a la iglesia católica, identificada tradicionalmente por los campesinos andaluces como la defensora de los privilegios de los ricos propietarios de la tierra, fue expoliado, o sencillamente destruido, en actos de euforia colectiva que pretendían simbolizar el final de un largo período histórico de dominio indiscutido de los grupos sociales que monopolizaban la tierra y la mayor parte de los recursos económicos disponibles (Cobo Romero, F., 1994).

Junto a estos actos de reafirmación de una voluntad colectiva de transformación, se procedió, a través de un esfuerzo de conducción de los deseos de cambio del campesinado, desplegado por los partidos y centrales sindicales de izquierda, a una extensa labor colectivizadora y de normalización de la vida cotidiana en la retaguardia leal A impulsos del Partido Socialista, el Partido Comunista y la Unión General de Trabajadores, se procedió a la constitución de múltiples comités, bajo la ditección del Ayuntamiento o del Comité Local del Frente Popular. Estos comités significaton la encarnación de la nueva relación de fuerzas establecida en extensas zonas rurales, y sin lugar a dudas fueron controlados mayoritariamente por los jornaleros o los campesinos pobres, asistidos de algunos otros miembros de los sectores populares (Quirosa-Cheyrouze, R., 1986 y Gil Bracero, R., 1995).

Paralelamente a la constitución de comités de abastecimientos, transportes, orden público, etc., el Partido Socialista Obrero Español, la Unión General de Trabajadores, el Partido Comunista de España y la Confederación Nacional del Trabajo realizaron una intensa labor colectivizadora de las grandes propiedades agrícolas abandonadas por sus antiguos propietarios, o sencillamente expropiadas.

Durante los años 1937, 1938 y 1939, a instancias sobre todo del Partido Comunista y del sector centrista del Partido Socialista, se asistió en tierras de la

Hípania, LIX/1, núm. 201 (1999) 75-96 
Alta Andalucia —al igual que ocurriera en el resto de la retaguardia republicanaa un gradual proceso de normalización política, institucional, económica y social. Los comités populares perdieron relevancia ante la superior capacidad administrativa adquirida desde comienzos de 1937 por los consejos municipales - donde estaban integrados tepresentantes de los distintos partidos y sindicatos del Frente Popular- (Gil Bracero, R, 1997 y Quirosa-Cheyrouze, R., 1997). Las colectividades recuperaton la tónica productiva caracterizada por la relativa reimplantación de relaciones salariales de producción. Se puso fin a los saqueos, expolios y asesinatos indiscriminados. En suma, se desplegó un intensísimo esfuerzo por edificar una economía de guerra, que sirviese a los objetivos fundamentales concomitantes con la organización de un ejército popular capacitado para triunfar en el conflicto. Los Consejos Municipales, en sustitución de los múltiples comités populares, continuaron encarnando la coalición de fuerzas sociales rurales defensoras del nuevo orden rural — campesino y jornalero- instaurado desde los primeros meses del conflicto.

\section{a) De los actos revolucionarios y otras actuaciones del campesinado}

La enorme fortaleza mostrada por el campesinado altoandaluz a la altura del verano de 1936, suponía un elemento francamente desequilibrador y rupturista con respecto a la pervivencia de las condiciones sobre las que permanecía edificado el orden rural tradicional, y colocaba en una situación de acusada inestabilidad a las relaciones de producción dominantes.

La guerra civil ocasionó una profunda y violenta transformación de las relaciones sociales alli donde fracasaron los intentos de involución fascista practicados por los sectores más tradicionalistas. En la práctica totalidad de las comunidades rurales de la Andalucía republicana, los componentes de los Ayuntamientos constituidos desde Febrero de 1936 se fusionaron con los Comités Populares, integrados básicamente por miembros de los partidos políticos y sindicatos de izquierda. Estos últimos desplegaron una intensa labor de control de la actividad local, hasta el punto de erigirse en auténticos órganos de ejecución de medidas de carácter transformador, siempre en beneficio de los sectores populares y campesinos y de sus específicos intereses culturales y materiales.

En la primera fase de la guerra, los comités populares fueron los auténticos dueĩos de una situación que podríamos calificar de revolucionaria. Practicaron detenciones de los propietarios derechistas más destacados, incautaron propiedades rústicas y llevaron a cabo colectivizaciones. En muchos casos, los Comités locales del Frente Popular, constituidos en formas embrionarias de las nueva situación del campesinado en la escala política y social de las comunidades rurales de la Alta Andalucía, entablaron múltiples vinculaciones - personales y derivadas de la mutua colaboración en la toma de decisiones acerca de los distintos aspectos de la vida económica y social de la comunidad-con los ayuntamientos resultantes de la primavera de 1936. La quiebra política del Es- 
tado republicano durante los primeros meses de la guerra civil, produjo una situación en numerosísimas comunidades rurales altoandaluzas de abierta persecución dirigida contra todos los representantes políticos de la derecha agraria y el falangismo, así como de todos aquellos integrantes de las denominadas «clases de servicio» que habían desempeñado un papel tutelar en la defensa de los intereses ideológicos y materiales de la gran patronal agraria. Así pues, el resultado inmediato del desencadenamiento de toda esta serie de acciones no fue otro que la constitución de gestoras municipales únicamente integradas por miembros de los partidos políticos y sindicatos del Frente Popular. A este último fenómeno, hay que añadir el espontáneo surgimiento de múltiples comités, encargados de canalizar las inquietudes políticas y económicas manifestadas por amplios colectivos populares hegemonizados por el campesinado o sus más conscientes portavoces. Lo que se produjo a partir de julio de 1936 en la práctica totalidad de los pueblos de la Alta Andalucía fue la fusión entre ayuntamientos frentepopulistas y comités populares. Los alcaldes, en muchos casos, se sintieron profundamente comprometidos e identificados con los acuerdos adoptados en el seno de los Comités locales del Frente Popular, como prueba el hecho de que muchos de ellos actuaban en calidad de primeras autoridades locales y presidentes del comité local respectivo (Gil Bracero, R., 1995 y Cobo Romero, F., 1994).

De esta manera, la fractura política y social significada por el fracaso del intento de golpe de estado derechista en amplias comarcas agratias de la Andalucía Oriental se tradujo, inmediatamente, en la formalización definitiva del Ayuntamiento -respaldado por los comités populares - como la primera instancia administrativa aprovechada totalmente por el campesinado para aplicar su específico modo de entender el aprovechamiento de la tierra y la organización económica y política de la colectividad rutal.

Tal y como ponen de manifiesto las fuentes documentales de la época y los acuerdos plenarios de los ayuntamientos, durante los primeros meses del conflicto, en la práctica totalidad de los pueblos de la Alta Andalucía que permanecieron en territorio leal, la mayor parte de las fincas rústicas y las fábricas de aceite de los medianos y grandes propietatios agrícolas fueron incautadas y puestas bajo el control de los comités populares. Los pattonos y aquellos otros destacados individuos que habían permanecido adscritos a la defensa de los valores del orden agrario tradicional, o bien fueron encarcelados o asesinados, o bien pudieron burlar el acoso de los más exaltados y lograron escapar hacia la zona controlada por los rebeldes (Gil Bracero, R., 1995 y Cobo Romero, F, 1994). El resultado de tales hechos fue el abandono de innumerables fincas y explotaciones agrarias, pertenecientes en su mayor parte a los miembros de las oligarquías rurales de cada localidad. De esta forma, las tierras, casas y propiedades de todo género abandonadas por los huidos o los represaliados, pasaron a ser ocupadas y administradas por los recién constituidos comités populares. El comité local del Frente Popular — a cuyo frente se hallaba generalmente el alcalde izquierdista de cada pueblo o ciudad-y los múltiples comités populares que permanecían inscritos en su órbita de influencia, comenzaron inmedia-

Hispania, 1.1X/1, nüm. 201 (199) 75-96 
tamente a administrar los fundos y demás propiedades que los patronos habían dejado de gestionar.

En suma, quedó enormemente reforzado el papel del poder municipal en la ordenación y gestión de los recursos materiales, políticos y culturales de la comunidad rural, adquiriendo en la coyuntura revolucionaria de los primeros meses de la guerra civil, un carácter de verdadero instrumento reformador utilizado por los sectores populares hegemonizados por los jornaleros y el campesinado en genetal.

\section{UN TRÁGICO EPILLGO. EL RÉGIMEN FRANQUISTA Y EL REGRESO A UNA NUEVA SITUACIÓN OLIGÁRQUICA EN LOS AYUNTAMENTOS}

La trágica experiencia de la guerra, y el reforzamiento extremo del poder jornalero y campesino en los ayuntamientos altoandaluces durante el transcurso del período 1936-1939, exacerbó aún más las posiciones contrapuestas que ya sostenían los grandes grupos sociales rurales desde el inicio de la década de los treinta. Debido a esta consolidación del poder campesino en los ayuntamientos, muchos ticos patronos, e incluso algunos pequeños propietarios y arrendatarios que se habían significado por su actitud antirrepublicana durante los meses previos al conflicto, resultaron gravemente dañados en sus intereses materiales y seriamente humillados por los colectivos más radicalizados de cada pueblo o ciudad. El transcurso de la guerta debilitó paulatinamente la capacidad productiva de muchas haciendas rústicas, y los trastornos políticos $y$ demográficos que sucedieron inmediatamente a la finalización del conflicto configuraron una situación de agudo estancamiento agrario (Cobo Romero, $\mathrm{F}$., 1996). Terminada la guerra civil, los patronos fueron restituidos en sus propiedades e intereses una vez que fue implantado el régimen franquista en las comarcas rurales altoandaluzas. Pero el enfrentamiento de clases había sido tan dramático en los años inmediatamente precedentes, que las viejas oligarquías rurales reclamaton su instalación en posiciones de privilegio, al frente de los ayuntamientos, para satisfacer sus más sentidos deseos. Entre estos últimos destacaremos dos de los más importantes. En primer lugar, el aniquilamiento de la red organizativa jornalera y campesina que tanto había perjudicado a los patronos durante los años de la república y la guerra civil. Para ello, los ricos propietarios rurales se emplearon a fondo en la instrumentalización, desde los ayuntamientos, de la cruel represión dirigida contra miles de jornaleros y campesinos pobres. En segundo lugar, la restauración de las condiciones económicas de la producción agraria necesarias para el relanzamiento de la capacidad productiva de las haciendas y explotaciones rústicas, para lo cual era requerido nuevamente el concurso de los ayuntamientos, ahora dirigidos por una élite rutal heredera del pasado caciquil y oligárquico. El régimen franquista, pues, proporcionó a las nuevas clases directoras del restaurado orden agratio de la gran propiedad, los instrumentos políticos locales necesarios para acometer los objetivos descritos. 
El final de la guerra, y el consabido triunfo de las tropas rebeldes, trajo consigo la implantación en todo el territorio nacional de un nuevo régimen, militarizado y autoritario, que abrazó las consignas del fascismo y practicó una violenta represión sobre los grupos políticos y sindicales representativos de los trabajadores industriales y el campesinado de extensas zonas de predominio latifundista y de la gran propiedad agraria. El Nuevo Estado franquista construyó un poderoso entramado institucional, para asegurar su reproducción normalizada y su continuidad en el tiempo. Una de las piezas fundamentales sobre las que se instalaba el aparato político-institucional del franquismo fue el poder municipal. Los ayuntamientos volvieton a erigirse en piezas clave para el reagrupamiento de los grupos sociales privilegiados que desde antes de la instauración del régimen de la II República integraban las coaliciones políticas defensoras del orden económico del capitalismo agrario. En Andalucía, así como en otras regiones agrícolas de predominio de la gran propiedad agraria, el poder local había sido tradicionalmente, y sobre todo durante la etapa de la Restauración, un instrumento indispensable, empleado por las oligarquías rurales para perpetuar su posición de dominio indiscutido sobre el tejido social rural. Así pues, no debe resultar extraño que el franquismo, como régimen político nacido de una renovada coalición de fuerzas sociales conservadoras que pretendieron la reimplantación de las condiciones históricas garantizadoras del modelo específico de desarrollo capitalista español, privilegiara nuevamente el poder local como instancia básica para el ejercicio de la represión sobre los vencidos, y la reconstrucción del entramado de relaciones de dominación específico del sistema agrícola de la gran propiedad (Cazorla Sánchez, A., 1994 y Cobo Romero, F., 1996).

Las comarcas altoandaluzas registraron una elevadísima conflictividad rural durante el período de la II República. Durante la guerra civil, los logros alcanzados por el campesinado - preferentemente por los jornaleros-_- de cara a la implantación de un nuevo orden social, fueron evidentes. La labor revolucionaria del campesinado de la Alta Andalucía durante el transcurso del conflicto civil provocó una sensación de terror y miedo entre numerosísimos miembros de la burguesía agraria y sus clases de servicio. Las privaciones de libertad, los asesinatos practicados sobre muchos derechistas o ricos propietarios, la expropiación de las medianas y grandes propiedades rurales, la extorsión y el expolio, en fin, causaron enormes trastornos en las vidas y haciendas de las viejas oligarquías. Todos estos hechos alimentaron un deseo de venganza histótica que se tradujo en la adopción de actitudes firmemente violentas, por parte de los grupos sociales perjudicados por la revolución, una vez reinstaurado el viejo orden de cosas.

Así pues, la naturaleza extremadamente violenta que presenta la represión de las autoridades franquistas dirigida contra los sectores populares altoandaluces - y muy especialmente sobre el campesinado- guarda una relación estrecha con todo lo acontecido durante la década de los treinta.

La radicalizada implantación de un nuevo uorden social» agtario, que devolvió sus posiciones de predominio a los miembros de la vieja oligarquía rural, 
permitió asimismo la emergencia de nuevas élites, vinculadas a los instrumentos del poder municipal franquista, o a los múltiples organismos que regulaton la compleja red de relaciones económicas tejida a partir de los años cuarenta.

Así pues, la crudeza con que actuaton las nuevas autoridades en las labores tepresivas contra los vencidos guarda una relación directa con el deseo de la burguesía rural altoandaluza por implantar una situación de acentuado terror, necesaria para la subordinación absoluta de la mano de obra jornalera que precisaba el proceso de acumulación capitalista reconstruido tras el final de la guerra. En la obtención de logros palpables en torno a tal empeño, los ayuntamientos volvieron a significar un objetivo insoslayable para las clases rurales nuevamente dominantes, incitando a las oligarquías agrarias hacia la articulación de agrupamientos de diversas personalidades locales que posibilitasen la correcta utilización - en un sentido de clase o grupo- de los poderes locales. Asimismo, pensamos que los desastres de la guerra civil, pero sobre todo las actuaciones concretas llevadas a cabo por las nuevas autoridades franquistas encaminadas a la edificación de un orden institucional anti-izquierdista y antirevolucionatio en aquellas comarcas de la Alta Andalucía que habían permanecido, a lo largo de casi todo el conflicto, bajo el control de las autoridades republicanas, provocaron agudas constricciones sobte el desenvolvimiento normalizado de la vida económica y social y auspiciaron el reforzamiento del caráctet periférico de la economía predominantemente agraria de buena parte de la Andalucía Oriental. En este sentido, la profunda crisis demográfica registrada en amplias comarcas agrícolas durante el periodo iniciado a partir de 1939, tiene mucho que ver con el excesivo reglamentismo en materia económica, la subordinación de la agricultura a las necesidades de la industria -instalada en regiones lejanas a Andalucia-, el sometimiento de los sectores populares a leoninas condiciones de existencia, y, en fin, la merma considerable — poblacional y de mano de obra disponible_- provocada por las ejecuciones llevadas a cabo por los tribunales militares o el encarcelamiento masivo de jornaleros, campesinos pobres u otros miembros de los sectores sociales más humildes.

Las provincias de Jaén, Granada o Almería, acentuaron su carácter periférico dentro del ordenamiento conjunto del capitalismo español, reforzando su especialización en actividades primarias o puramente agrícolas. A esta intensificación del fenómeno periferizador contribuyó la labor de las nuevas autoridades franquistas, que persiguiendo el objetivo de restituir a la burguesía agraria su antigua posición prevalente, posibilitaron el incremento notabilísimo de las ganancias capitalistas en las explotaciones agrarias, gracias a la congelación salarial y la destrucción de los instrumentos políticos y sindicales de defensa de los grupos populares y el campesinado. La abundancia de la mano de obra agrícola, así como su baratura, prefiguraron una situación de ventajas comparativas acusadamente favorecedotas de la inversión en la agricultura, y el desprecio de otras orientaciones inversoras destinadas a la extensión de una mínima red industrial.

Tras la victoria franquista, los ayuntamientos recuperaron su condición de baluartes indispensables de las clases dominantes, empleados en la consolida- 
ción de su posición de dominio económico, político e ideológico sobre el testo de la sociedad mediante reparto de prebendas, asignación de recursos, regulación del mercado de trabajo, distribución desigual de las cargas impositivas, etc.

Igualmente desde los ayuntamientos la oligarquía local controlaba políticamente al campesinado imponiendo una férrea disciplina, castigando severamente a los sospechosos de desobediencia al nuevo régimen y condenando, en suma, a la postergación y a la miseria a los campesinos de izquierda y sus más directos familiares. Sin duda, el poder local fue uno de los cimientos para construir el nuevo edificio de la dominación política del franquismo. Los múltiples actos de naturaleza tepresiva del régimen contaban con el concurso indispensable de las corporaciones locales, por lo que, nuevamente, su control por parte de la oligarquía dominante se tornaba de todo punto imprescindible.

Al menos en tres frentes decisivos orientaron su actividad las nuevas autoridades municipales franquistas:

1) En el ámbito correspondiente a las tareas de represión, condena, encarcelamiento o coacción dirigidas, en su mayoría, contra aquellos miembros del campesinado que mostraron un comportamiento revolucionario o decididamente antipatronal durante el período histórico inmediatamente precedente.

2) En la esfera de la asignación de recursos materiales y productivos a los tradicionales grupos sociales dominantes, a fin de restablecer su posición privilegiada en el acceso y la utilización de los medios de producción aseguradores de su destacada posición de privilegio.

3) En lo concerniente a la utilización, con un sentido «de clase o grupo", de cuantos instrumentos administrativos hiciesen posible el disciplinamiento del mercado de trabajo, factor indispensable en la recuperación de la rentabilidad de las explotaciones agrícolas (Cobo Romero, F, 1996).

En el primero de los espacios de actuación delimitados, los Ayuntamientos, y muy especialmente la figura de los nuevos alcaldes (en la mayoría de los casos pertenecientes a la vieja oligarquía agraria o a los cuadros dirigentes de Falange Española Tradicionalista y de las J.O.N.S.), colaboraron estrechamente con las autoridades militares en las labores de depuración y exterminio de los considetados enemigos del Nuevo Régimen. En la práctica totalidad de las cabeceras de partido judicial, constituyéronse Juzgados de Instrucción y Tribunales Militares Especiales que incoaron expedientes sancionadores contra cientos de campesinos y miembros de los sectores sociales populares, inculpados del delito de rebelión o de usurpación indebida de las propiedades rústicas de los ricos hacendados locales. La conjunción de las fuerzas de la Guardia Civil, las autoridades municipales y la dirección local de Falange hicieron posible el encarcelamiento de miles de campesinos y su posterior enjuiciamiento. El alcalde se constituyó asimismo en figura destacada en la colaboración con los Tribunales Regionales de Responsabilidades Políticas, al emitir un gran número de informes socio-políticos contra los considerados contrarios al régimen o reacios a los dictámenes de las nuevas autoridades.

Los Ayuntamientos franquistas recuperaron una gran parte de las atribuciones de que gozaban, antes de la proclamación de la II República, en materia

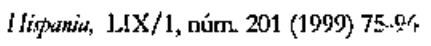


de distribución de recursos. La tarea más importante desempeñada por las autoridades municipales franquistas consistió en la intervención administrativa y posterior devolución a sus antiguos titulares de las tierras, enseres y medios técnicos de producción expropiados por el Instituto de Reforma Agraria o incautados por los Comités Populares y Colectividades Agrícolas que proliferaton durante el transcurso de la guerta. Las Juntas Municipales de Recuperación Agrícola, adscritas al Servicio Nacional de Recuperación Agrícola y dependientes del Servicio Nacional de Reforma Económica y Social de la Tierra, desplegaron una intensa labor de restauración del patrimonio rústico de las antiguas oligarquías rurales. Asimismo, los Ayuntamientos tenian competencias especiales en los repartos de utilidades, asignación de créditos a los cultivadores de trigo (a través de las Juntas Agrícolas Locales), concesiones en atriendo de los aprovechamientos de pastos y rastrojeras, imposición del trabajo obligatorio en función de la premura de ciertas faenas agrícolas (mediante la actuación de las Juntas Agrícolas para la intensificación del cultivo en el campo), etc.

Por último, las autoridades municipales franquistas efectuaban una indispensable labor de auxilio a las necesidades económicas exigidas por las explotaciones rústicas de los medianos y grandes propietarios agtícolas. Un instrumento esencial destinado a garantizar la sobreexplotación de la mano de obra campesina lo constituyeron las Comisiones Municipales de Colocación obrera. Estas últimas estaban integradas por un representante del Ayuntamiento, el delegado sindical local y otros representantes patronales y obreros designados por el delegado sindical local. Muy probablemente, desde estas Comisiones se ejerció una clara discriminación contra los campesinos más conscientes y combativos.

\section{BIBLIOGRAFÍA CITADA}

ARóstegui, Julio, (Coord.), (1988), Historia y Memoria de la Guerra Civil. Encuentro en Castilla y León, 3 vols., Valladolid, Consejería de Cultura y Bienestar Social de la Junta de Castilla y León.

ARRARÁS (IRIBARUEN), Joaquín, (1940-1943), Historia de la Cruqada Española, Madrid, Ediciones Españolas.

ARTILLO GONZÁLEZ, Julio, (1982), «Jaén, siglos XIX y XX", en José RoDRíGUEZ MOLINA (et alii.), Historia de Jaén, Jaén, Excelentisima Diputación Provincial.

BARCIELA LÓPEZ, Carlos, (1981), «El estraperlo de trigo en la posguerra», en Moneda y Crédito, $n^{\circ} .151$.

- (1986), «El mercado negro de productos agrarios en la posguerra, 1939-1953», en Josep FONTANA, España bajo el franquismo, Barcelona, Crítica, pp. 192-205.

- (1986, bis), «Los costes del franquismo en el sector agrario: la ruptura del proceso de transformaciones. Introducción, en Ramón GARRABOU (et alii.), Historia agraria de la España Contemporánea, Vol. III.- «El fin de la agricultura tradicional. (1900-1960)», Barcelona, Crítca.

- (1989), «La España del Estraperlo», en Manuel TUÑ́́ DE LARA (dir.), El primer franquismo. España durante la Segunda Guerra Mundial, $N$ Coloqujo de Histona Contemporánea de España), Madrid, Siglo XXI, pp. 105-122.

BERNALDO DE QUIRÓs, Constancio, (1973), El «Espartaquismo Agranio" y otros ensayas sobre la estructura económica y social de Andalucia, Madrid, Ediciones de la Revista de Trabajo. 
BIGLINO, Paloma, (1986), El socialismo españoly la cuestión agraria (1890-1936), Madrid, Ministerio de Trabajo y Seguridad Social.

CALliro AMOR, Antonio Maria, (1979), Movimientos sociales en Andalucia, (1820-1936), Madrid, Siglo XXI.

CAsTiLLO, Juan José, (1979), Propietarios muy pobres. Sobre la subordinación politica del pequeño campesino en España. (La Confederación Nacional Católico-Agraria, 1917-1942), Madrid, Ministerio de Agricultura.

CASTRO, Concepción de, (1979), La Revolución Liberal y los municipios españoles, Madrid, Alianza Editorial.

CAZORLA SÁNCHEZ, Antonio, (1994), El campesinado almeriense bajo el franquismo, 1939-1975. Politica y economía en el desarrollo de una clase social, Tesis Doctoral, Granada, Universidad, Servicio de Publicaciones. Edición microfichada.

COBO ROMliRO, Francisco, (1991), La conflictividad campesina en la provincia de Jaén durante el período 1931-1939, Tesis Doctoral, Universidad de Granada, Microfichas.

- (1992), Labradores, campesinos y jornaleros. Protesta social y diferenciación interna del campesinado jiennense en los origenes de la guerra civil (1931-1936), Córdoba, Ayuntamiento.

- (1994), La Guerra Civily la Represión Franquista en la provincia de Jaén, (1936-1950), Jaén, Instituto de Estudios Giennenses.

- (1995), «La II República, la Guerra Civil y la primera etapa del Franquismo en la provincia de Jaény, en Luis GARRIDO GONZÁLEZ (Coord.), Nueva Historia Contemporánea de la provincia de Jaén, (1808-1950), Jaén, Diputación Provincial.

COBO ROMERO, F., (1996), El maro politico y socio-económico de la represión franquista en la prouincia de Jaén, 1939-1953, Ponencia presentada al II Curso de Historia Contemporánea de la Universidad de Otoño de Andújar. Inédito.

COBO ROMERO, F; CRUZ ARTACHO, S. y GONZȦLIZZ DE MOLINA, M., (1992), «Privatización del monte y protesta campesina en Andalucía Oriental (1836-1920)", en Agricultura y Sociedad, $^{\circ}$. 65, pp. 253-302.

COI.LIER, G.A. (1997), Socialistas de la Andalucia rural. Los revolucionarios ignorados de la Segunda Repúbtica, Barcelona, Anthropos.

CRUZ ARTACHO, Salvador (1992), Caciquismo, orden social y conflictividad nural en Granada, 18901923 (Estructura de poder y luchas agrarias). Tesis Doctoral. Granada, Universidad de Granada.

- (1994), Caciques y campesinos. Poder politico, modernización agraria y conflictividad rural en Granada, 1890-1923, Madrid, Ediciones Libertarias.

DIAZ DEL MORAL, Juan, (1979), Historia de las agitaciones campesinas andaluzar, Madrid, Alianza Editotial.

EsluÑ $\Lambda$. Leyes, (1939), Resumen legislativo de/ Nuevo Estado, Barcelona, Editora Nacional.

ESIEBAN, Joan M., (1978), «La política económica del franquismo: una interpretación», en Paul PRESTON, (et alii.), España en crisis. Evolución y decadencia del régimen de Franco, Madrid, Fondo de Cultura Económica.

FraSER, Ronald, (1986), Escondido. El calvario de Manuel Cortés, Valencia, Institució Alfons el Magnanim.

GARCí DELGADO, José Luis, (1987), «La industrialización y el desarrollo económico de España durante el franquismon, en NADAJ. OLLER, J., (et alii.), La economia española en el siglo XX. Una perspectiva bistórica, Batcelona, Ariel.

GARRABOU, Ramón, (et alii), (1986), Historia agrania de la España Contemporánea. Vol. III, El fin de la agricultura tradicional (1900-1960), Barcelona, Crítica..

- (et alii.), (1988), La crisis agraria de fines del siglo XIX, Batcelona, Crítica.

GARRIDO GONZÁLLZ, Luis, (Coord.), (1995), Nueva Historia Contemporánea de la provincia de Jaén, (1808-1950), Jaén, Diputación Provincial.

GARRIDO GONZÁLEZ, Luis, (1979), Colectividades agrarias en Andahuia: Jaên (1931-1939), Madrid, Siglo XXI.

- (1981), «Producción agrícola en la España Republicana», en Estudios de Historia Social, $\mathrm{N}^{\mathrm{D}} .16-19$.

Hitpania, LIX/1, núm. 20‡ (1999) 75-96 
- (1985), «La agricultura en la Andalucía Republicana durante la Guerra Civil (1936-1939)", en Actas del III Coloquio de Historia de Andalucia. Andalucia Contemporánea, Cótdoba, Publicaciones del Monte de Piedad y Caja de Ahorros de Córdoba, pp. 139-142.

- (1987), «Legislación social y conflictos laborales en la provincia de Jaén (1931-1933), en Manuel TuÑón DE LARA (dir) y José Luis GNRCIA DELGADO (ed.), La II República. Elprimer bienio, (III Coloquio de Segovia sobre Historia Contemporánea de España). Madrid, Siglo XXI

- (1990), Riqueza y tragedia social. Historia de la clase obrera en la provincia de Jaén (1820-1939), Jaén, Excelentísima Diputación Provincial, 2 vols.

GEA (Grupo de Estudios Agrarios), (1995), "Transformaciones agratias y cambios en la furcionalidad de los poderes locales en la Alta Andalucia, 1750-1950 s, en Noticiario de Historia Agraria, ñ. 10 , pp. 35-66.

GEHR (Grupo de Estudios de Historia Rural), (1988), «Crisis y cambio en el sector agrario: Andalucía y Extremadura, 1875-1935", en Ramón GARRABOU (et alii.), La crisis agraria de fines del siglo XIX, Barcelona, Critica, pp. 161-179.

GIi BRACERO, Rafael, (1995), Guerra Cinil en Granada, 1936-1939. Una revolución frustrada y la liquidación de la experiencia republicana de los años treinta, Tesis Doctoral, Granada, Universidad, Servicio de Publicaciones. Edición microfichada..

- (1997): Motril en Guerra. De la República al Franquismo (1931-1939). La República vencida, Granada, Ediciones y Proyectos Culturales Mediterráneos.

GONZÁLEZ DE MOLINA, Manuel, (1993), «La funcionalidad de los poderes locales en una economia orgánica", Noticiario de Historia Agraria, $\mathrm{n}^{\circ}$. 6, pp. 9-23.

GuTiĹRREZ DEL CASTILLO, Carmen, (1983), "Una estimación del mercado negro de aceite de oliva en la posguerra españolan, en Agnicultura y Sociedad, n². 29, (Octubre-Diciembre), pp. 153-173.

HERNÁNDEZ ANDREU, Juan, (1980), Depresión económica en España, 1925-1934. Crisis mundial antes de la Guerra Civil Española, Madrid, Instituto de Estudios Fiscales.

HERNÁNDEZ ARMENTEROS, Salvador, (1988), Jaén ante la Segunda República. Bases económicas, sociales y politicas de una transicion, Granada, Universidad de Granada. Fundación «Paco Natetas.

JiMÉNEZ BLANCO, José Ignacio (1986), La producción agratia en Andalucia Oriental, 1874-1914. Madtid, Universidad Complutense de Madrid (Edición facsímil).

LACOMBA, Juan Antonio, (1986), «La represión en Andalucía durante la Guerra Civil. El asesinato de Blas Infantes, en Arbor, (Monográfico dedicado a la Guerra Civil Española), $\mathrm{n}$. 491-492, Tomo CXXV, (Noviembre-Diciembre), pp. 121-151.

LEAL, José Luis; LEGUINA, Joaquín; NAREDO, José Manuel y TARRAFETA, Luis, (1986), La agricultura en el desarrollo capitalista español, 1940-1970, Madrid, Siglo XXI.

LÓPEZ MANJóN, Juana, (1986), ... Y quién sog yo?, memorias de la Guerra Civilen Úbeda, Úbeda, La Autora.

LÓPEZ MARTINEZ, Mario, (1992), Electiones, caciques y campesinos en Granada durante la Segunda República (1931-1936). (Orden público y control social en las comunidades rurales), Granada, Tesis Doctoral, Mictofichas.

- (1995), Orden puiblico y luchas agrarias en Andalucia. Granada, 1931-1936, Madrid, Ediciones Libertarias.

LÓPEZ MARTÍNEZ, M. y GIL BRACERO, R. (1997): Motril en Guerra. De la República al Franquismo (1931-1939). La Utopia Revolucionaria, Granada, Ediciones y Proyectos Culturales Mediterráneos.

MALEFAKIS, Edward, (1982), Reforma agraria y revolución campesina en la España del sigh XX, Barcelona, Ariel.

MARTíN VILLODRES, Enrique, (1932), La verdad desnuda. (Misoviet en Jaén), Madrid, Imprenta Sáez Hermanos.

MAKTINEZ MAR'líN, Manuel, (1995), Mancha Real: un modelo de crecimiento agrario y campesinización, (1750-1875), Jaén, Servicio de Publicaciones de la Universidad de Jaén. 
MINISTERIO DE TRABAjO Y PREVISIÓN. (Dirección General de Acción Social), (1931), La crisis agraria andaluza de 1930-1931. Estudios y documentos, Madrid, Imprenta Helénica.

MORENO GÓMEZ, Francisco, (1989), «La represión en la España campesinas, en Manuel TUNÓN DE LARA (dir), El primer franquismo. España durante la Segunda Guerra Mundial, (V Coloquio de Historia Contemporánea de España), Madrid, Siglo XXI.

MUÑOZ FERNÁNDEZ, Antonia, (1960), «La emigración en la provincia de Jaén, 1900-1955», en Estudios Geográficos, nº. 81.

NúÑEZ DEIGADO, Montserrat, (1997), Pinos Puente en la Edad Contemporánea: auge y decadencia de una economía agriala (1750-1936), Trabajo de investigación de Doctorado. Granada, Facultad de Filosofia y Letras.

PALAFOX, Jordi, (1991), Atraso económico y democraciar la Segunda República y la Economia Española, 1892-1936, Barcelona, Crítica.

PÉREZZ YRUELA, Manuel, (1979), La conflictividad campesina en la provincia de Córdoba, (1931-1936), Madrid, Ministerio de Agricultura-Secretaría General Técnica.

POZUElO, Nemesio, (s/f), Algunos datos fundamentales ocurridos en Jaén durante los primeros días de la sablevación fascista, Moscú.

PRESTON, Paul, (1978), La destrucción de la democracia en España. Reacción, reforma y revolución en la Segunda Repriblica, Madrid, Turner.

- (et alii.), (1986), Revolución y guerra en España, 1931-1939, Madrid, Alianza Editorial.

QUirosa-CHEYRouZE MUNOZ, Rafael, (1986), Politica y Guerra Civil en Almeria, Almeria, Caja.

- (1997): Almería, 1936-37. Sublevación militar y atteraciones en la retaguardia republicana, Almeria, Universidad-Servicio de Publicaciones.

SEVIJLA GUZMÁN, Eduardo, (1979), La evolución del campesinado en España. Elementos para una sociologia politica del campesinado, Barcelona, Península.

SORA, Georges, (1978), Guerray Revolución en España, 1936-1939, Batcelona, Grijalbo, 5 vols.

SORNI MANES, José, (1978), «Aproximación a un estudio de la contrarteforma agraria en Españam, en Agricultura y Sociedad, n. 6, (Enero-Marzo), pp. 181-216.

THOMPSON, Edward P., (1968), The Making of the English Working Class, Hardmondsworth, Penguin.

- (1971), "The Moral Economy of the English Crowd in the Eighteenth Century", en Past and Present, $\mathrm{n}^{\circ} 50$ (Febrero), pp. 76-136.

TUNÓN DE LARA, Manuel, (1985), Tres claves de la Segunda República. La cuestión agraria, los aptaratos del Estado, Frente Popular, Madrid, Alianza Editorial.

TuŃón DE LARA, Manuel (dir.) y José Luis GARCIA DELGADO (ed.), (1987), La II República. El primer biento, (III Coloquio de Segovia sobre Historia Contemporánea de España). Madrid, Siglo XXI

WRIGLEY, E.A., (1988), Continuity, Chance and Change. The Character of Industrial Rewolution in Entgland, Cambridge, Cambridge University Press.

Hispania, L1X/1, núm. 201 (1999) 75.96 